\title{
Metasezgisel Optimizasyon Yöntemlerin Performanslarının Basit Bir Su Dağıtım Şebekesi Kullanılarak Araştırılması
}

\author{
Utku ZEYBEKOĞLU \\ Sinop Üniversitesi, Boyabat Meslek Yüksekokulu, Boyabat, Sinop, Türkiye
}

Sorumlu Yazar: utkuz@ sinop.edu.tr

Geliş Tarihi: 14.09 .2017

Kabul Tarihi: 10.11 .2017

Özet

Bilimsel ve teknolojik gelişmelerle birlikte artan nüfusun etkisiyle yeryüzündeki suyun paylaşımı ve kullanımı günden güne daha da önem kazanmaktadır. Yeryüzünde bu kadar değerli olan bu maddenin tasarruflu ve yeterince kullanılması bir zorunluluk haline gelmektedir. Sunulan bu çalışmada basit bir su dağıtım şebekesindeki borulardaki suyun taleplere göre en uygun şekilde belirlenmesi amaçlanmıştır. Bu amaçla Guguk Kuşu ve Ateşböceği Algoritmaları kullanılarak örnek şebekenin çözümü gerçekleştirilmiş olup literatürdeki sonuçlarla birlikte incelenmiştir. Şebekenin Guguk Kuşu Algoritması kullanılarak çözümünün diğer algoritmaya oranla daha iyi sonuç verdiği belirlenmiştir.

Anahtar Kelimeler: Su Dağıtım Şebekesi, Guguk Kuşu Algoritması, Ateşböceği Algoritması.

\section{Investigation of the Performance of Metaheuristic Optimization Methods by Using a Simple Water Distribution Network}

\begin{abstract}
Scientific and technological developments together with the effect of increasing population, the sharing and usage of water on the earth gains more importance from day to day. It is a necessity that this material which is so valuable on the earth is to be saved and used adequately. In this study, it is aimed to determine the optimum conditions of the water in the pipes in a simple water distribution network. For this purpose, the solution of the sample network has been realized by using the Cuckoo Search and Firefly Algorithms and examined together with the results in the literature. It has been determined that the solution of the network using the Cuckoo Search Algorithm is better than the other algorithms.
\end{abstract}

Keywords: Water Distribution Network, Cuckoo Search Algorithm, Firefly Algorithm. 


\section{Giriş}

Yeryüzündeki insan, hayvan, bitki ve diğer canlıların yaşamlarını devam ettirebilmesi için ihtiyaç duyduğu maddelerden biri olan suyun yaklaşık \%3 kadarı tatlı sular oluşturmaktadır. Bu tatlı suların ise yalnızca \%1'lik kısmı ulaşılabilir durumda bulunmaktadır. Bu kadar sınırlı bulunan suyun gerektiği kadar kullanılması gerekmektedir.

İnsan yaşamının vazgeçilmez ögesi olan su tarih öncesinden itibaren çeşitli yöntemlerle yaşam alanlarına getirilmektedir (Erdin, 2001). Çağlar geçtikçe teknolojideki ilerlememelerin yanı sıra artan nüfusun ve ihtiyaçların da artması sonucunda şebekelerdeki su dağıtımı önem arz etmiştir. Günümüzde nüfusun yanı sıra şebekelerin de daha komplike bir hal alması şebekelerin tasarımını ve suyun paylaşımı konusunu daha da önemli bir hale getirmiştir.

Su dağıtım şebekelerinin optimal tasarımı konusundaki araştırmalar 1960'lı ve 1970'li yıllara dayanmaktadır. (Suribabu, 2012). Araştırmacılar değişik su dağıtım şebekeleri üzerine farklı yöntemler uygulayarak çalışmalar ortaya koymuşlardır. Bu çalışmalardan başlıcalarını Schaake ve Lai (1969) Dinamik Programlama; Simpson ve ark. (1994) Genetik Algoritma; Afshar ve Marino (2005) Genetik Algoritma; Geem (2009) Parçacık Sürü Optimizasyon Yöntemini ve Armoni Araştırması Yöntemini birlikte; Vasan ve Simonovic (2010) Diferansiyel gelişim Algoritması; Baek ve ark. (2010) Armoni Araştırması Algoritmasını; Suribabu (2010, 2012) Diferansiyel Gelişim Algoritması ve Sezgisel Tabanlı Algoritma; Zheng ve ark. (2011, 2012, 2013) Diferansiyel Gelişim Algoritması; Ezzeldin ve ark. (2013) Parçacık Sürü Optimizasyon Tekniği; Sevük ve Altınbilek (1977) Eşdeğer boru Yöntemi; Koç ve ark. (2003) Genetik Algortima ve Newton Yöntemi; Kahraman ve Özdağlar (2004) Genetik Algoritma; Karahan ve ark. (2005) Genetik Algoritma; Özdağlar ve ark. (2006) Genetik Algoritma; Ayvaz ve ark. (2007) Armoni Araştırması Optimizasyon Tekniği; Yılmaz (2015) Yapay Arı Kolonisi, Parçacık Sürü Optimizasyon Tekniği ve Genetik Algoritma kullanılarak gerçekleştirilmiş çalışmalar oluşturmaktadır.

Sunulan bu çalışmada Sezgisel Optimizasyon Algoritmaları arasında yer alan ve yazarın bildiği kadarı ile su dağıtım şebekeleri üzerine henüz uygulanmayan Ateşböceği ve Guguk Kuşu Algoritmaları kullanılarak basit bir su dağıtım şebekesi üzerinde algoritmaların performansları araştırılmıştır.

\section{Metot}

\subsection{Ateş Böceği Algoritması}


Ateş böceği algoritması (firefly algorithm) Dr. Xin She Yang da ateş böceklerinin parlaklık modelleri ve hareket yönleri dikkate alınarak Cambridge Üniversitesi'nde tasarlanmış ve uygulanmıştır. Algoritmanın üç ana prensibi bulunmaktadır.

- Ateşböceği unisextir, böylece bir ateşböceği cinsiyeti ne olursa olsun kendine diğer ateş böceklerini çekebilir.

- Çekicilik, parlaklıkla orantılıdır ve aralarındaki mesafe arttıkça azalır.

- Böylece, her iki yanıp söner ateş böcekleri için, daha az parlak ateş böceği daha parlak ateş böceği tarafına hareket edecek. Eğer daha parlak kimse yoksa o zaman rastgele hareket edecek.

Ateşböceğinin parlaklığı amaç fonksiyonun düzenlenmesi ile belirlenir. Algoritmada,

$\mathrm{N}$ tane ateş böceği sürüsü kullanılmakta, $\mathrm{x}_{\mathrm{i}}$ : i. Ateş böceğinin çözümü, $\mathrm{f}\left(\mathrm{x}_{\mathrm{i}}\right)$ : Çözümün maliyetini(En iyiye olan uzaklığını), tüm ateş böcekleri için problem boyutu kadar elemana sahiptir ve rastgele değerlerle ilişkilenmektedir. Her bir aday çözümün eniyileyecek problemden döndürdüğü değer kadar ilgili ateş böceğinin parlaklık/1şık yoğunluğunu $I$ ifade etmektedir (Yang,2008).

$\mathrm{N}$ tane ateş böceği sürüsü kullanılmakta, $\mathrm{x}_{\mathrm{i}}$ : i. Ateş böceğinin çözümü, $\mathrm{f}\left(\mathrm{x}_{\mathrm{i}}\right)$ : Çözümün maliyetini(En iyiye olan uzaklığını), tüm ateş böcekleri için problem boyutu kadar elemana sahiptir ve rastgele değerlerle ilişkilenmektedir. Her bir aday çözümün eniyileyecek problemden döndürdüğü değer kadar ilgili ateş böceğinin parlaklık/ışık yoğunluğunu $I$ ifade etmektedir (Yang, 2008). Işık yoğunluğu Denklem 1'deki gibi hesaplanmaktadır.

$$
I=I_{0} e^{-\gamma r}
$$

Denklem 1'de; $I_{0}$ : başlangıç 1şık yoğunluğu, $\gamma:$ 1şık soğurma katsayısı, $r$ : iki ateş böceği arası uzaklık olarak ifade edilmektedir.

Ateş böceğinin çekiciliği parlaklığa ve uzaklığa bağlıdır ve Denklem 2'de gösterildiği gibidir.

$$
\beta=\beta_{0} e^{-\gamma r}
$$

Denklem 2'de; $\beta$ : Ateş böceğinin çekiciliği, $\beta_{0}$ : İki ateş böceği arasındaki uzaklığı gösteren r'nin 0 olduğundaki çekicilik değeri $\beta_{0} 0$ ile 1 arasında değer alabilmektedir. $\beta$ İfadesindeki değere bağlı olarak az çekici olan i. Ateş böceği kendisinden daha çekici olan j. Ateş böceğine doğru hareket eder (Yang, 2008). Yapılan bu hareket Denklem 3'ile ifade edilmektedir. 


$$
x_{i}^{t+1}=x_{i}+\beta_{0} e^{\left(-\gamma_{i j}^{2}\right)}\left(x_{j}-x_{i}\right)+\alpha \varepsilon_{i}^{t}
$$

Denklem 3 'te; $x_{i}$ : . Ateş böceğinin aday çözümü, $x_{j}$ : Ateş böceğinin aday çözümü, $\varepsilon$ : Gauss dağglımı ile belirlenir.

İki ateş böceğindeki uzaklık Denklem 4'te bulunan Kartezyen(Cartesian) uzaklık formülü ile belirlenir (Yang,2008).

$$
r_{i j}=\left|x_{i}-x_{j}\right|^{2}=\sqrt{\sum_{k=1}^{d}\left(x_{i, k}-x_{j, k}\right)^{2}}
$$

Çoğu uygulamalarda, popülasyon büyüklüğünü = 15 - 100'e kadar kullanabilir ve en iyi dizi 25 - 40'a kadardir (Yang, 2008, 2009, 2013).

Araştırmacılar, Ateş Böceği Algoritmasının literatüre kazandırılmasından sonra algoritmayı iyileştirmeyi amaçlayan çalışmaların yanısıra, algoritmayı kullanarak problemler çözmüşlerdir. Bu çalışmalardan bazıları; Lukasik ve Zak(2009); Gandomi ve ark.(2011); Farahani ve ark. (2011); Khadwilard ve ark.(2011); Yang ve He (2013); Uz(2014); Özyüksel ve ark. (2017); Değertekin ve ark. (2015); Karaaslan ve Zengin (2016); Belen ve ark. (2014) gerçekleştirmiş oldukları çalışmalardır.

Ateşböceği Algoritmasının sözde kodu, Sözde Kod 1'de gösterilmektedir.

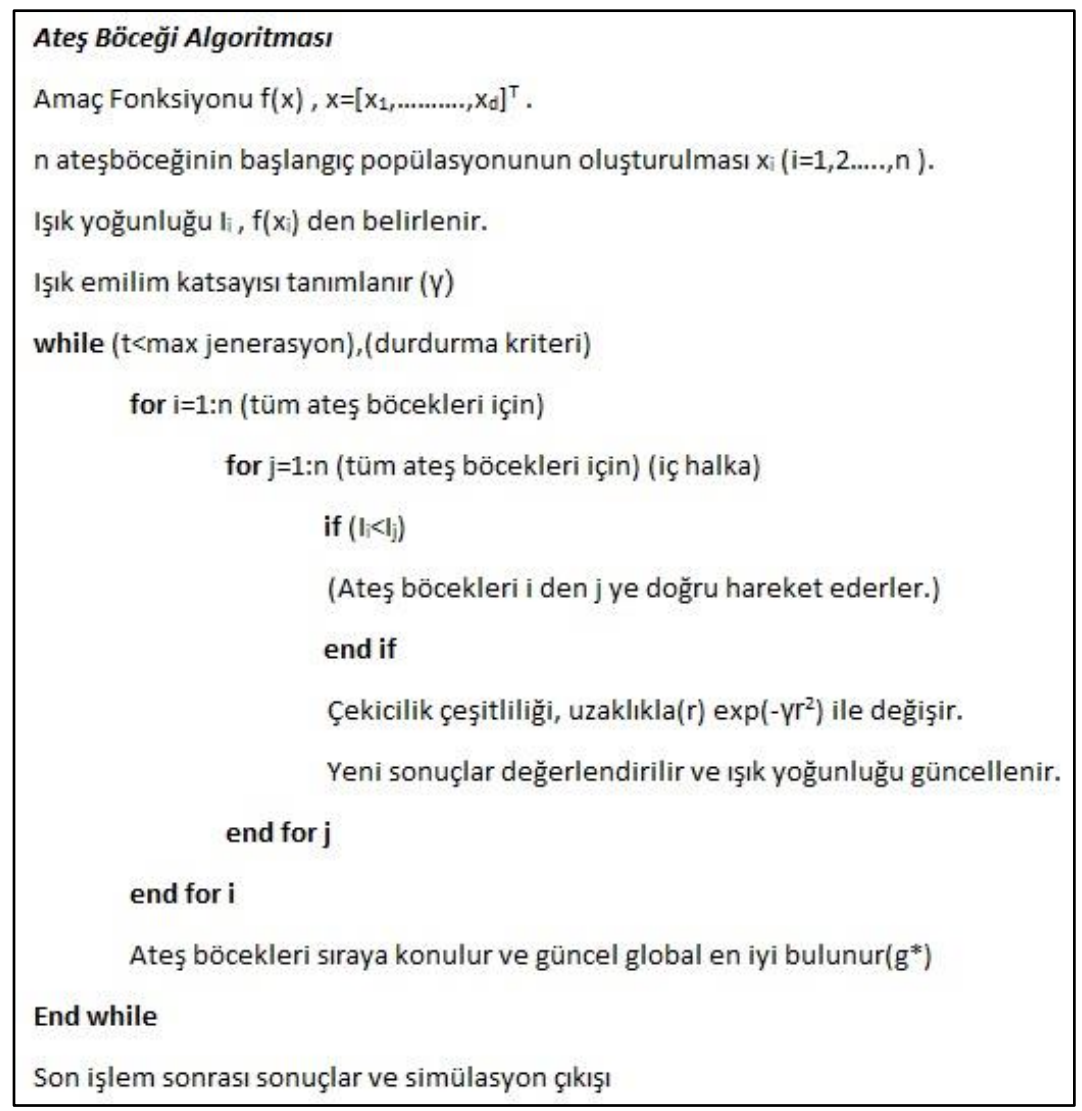

Sözde Kod 1. Ateş Böceği Algoritması 


\subsection{Guguk Kuşu Algoritması}

Guguk kuşu algoritması(cuckoo search algorithm) Dr. Xin She Yang ve Dr. Suash Deb tarafından guguk kuşlarının çoğalma davranışlarından esinlenerek tasarlanmış ve geliştirilmiştir. Algoritmanın ilham kaynağı kuluçka parazitliğidir (Yang ve Deb,2009). Guguk kuşları, kendi yuvaları dışında başka canlıların yuvalarında yumurtlamaktadırlar ve yumurtaladıkları yuvadaki yuva sahibi canlıların yumurtalarından yavru çıkma olasılığı yüksek yumurtaları yuvadan atmaktadır. Diğer taraftan yuvanın sahibi de guguk kuşunun yumurtasını tanırsa yumurtayı atar veya o yuvayı terk etme davranışını göstermektedir. Fakat yuva sahibi yumurtaları tanıyamazsa guguk kuşunun yumurtalarına da kendi yumurtaları gibi üzerine oturarak kuluçka parazitliği durumu ortaya çıkar. Algoritmanın üç ana prensibi vardır (Yang ve Deb,2009; Yang,2014).

- Her kuş bir tane rastgele yuvaya bir tane yumurta bırakabilir.

- Yuvada kaliteli yumurta varsa bir sonraki nesle aktarılmaktadır.

- Konak yuvanın sahibi, bırakılan yumurtayı belirli bir $p_{a}(0,1)$ olasılı̆̆ında tanıyabilmektedir. Eğer yumurtayı tanırsa, yumurtayı yuvadan aşağı atabilir veya yuvayı terk ederek kendisine yeni bir yuva inşa edebilir.

Sezgisel optimizasyon(en iyileme) algoritmaları en iyi çözüme yaklaşırken global ve lokal arama yapmaktadırlar. Algoritmaların varsa olası diğer çözümleri bulabilmeleri için keşfe çıkmaları gerekmektedir (Yang,2008; Gandomi ve ark.,2013).

Bu yüzden guguk kuşu algoritması rassal yürüyüş ve lokal rassal yürüyüş yaklaşımlarının bir arada dengede kullanıldığı bir algoritma olmuştur. Bu yürüyüş hareketi manevra parametresi $\left(p_{a}\right)$ tarafından kontrol edilmektedir (Yang,2014; Karagül,2014). Yerel rassal yürüyüş Denklem \%5'teki gibidir.

$$
x_{i}^{t+1}=x_{i}^{t}+\alpha S \otimes H\left(p_{a}-\epsilon\right) \otimes\left(x_{j}^{t}-x_{k}^{t}\right)
$$

Denklemde $x_{j}^{t}$ ve $x_{k}^{t}$ rassal permutasyonla belirlenmektedir. $H(u)$ Heaviside adım fonksiyonu veya birim adım fonksiyonu olarak adlandırılırken $\in$ parametresi düzgün dağılımdan gelen rassal sayıyı ve $S$ adım büyüklüğünü ifade etmektedir (Yang,2014; Karagül,2014).

Global rassal yürüyüşü ise Denklem 6 'da bulunan Levy uçuşu ile ifade edilir. Fonksiyondaki L ifadesi Denklem 7'de verilmektedir. 


$$
\begin{aligned}
& x_{i}^{t+1}=x_{i}^{t}+\alpha L(s, \lambda) \\
& \left.L(s, \lambda)=\frac{\lambda \Gamma(\lambda) \sin (\Pi \lambda / 2)}{\Pi} \frac{1}{s^{1+\lambda}}(s\rangle>s_{0}>0\right)
\end{aligned}
$$

Levy uçuşu, yeni nesiller üretebilmek için gerçekleştirilir. Burada olmak üzere problemin büyüklüğüne bağlı olarak Levy uçuşunu ölçeklendirmektedir (Yang ve Deb, 2009; Yang, 2014; Karagül, 2014).

Araştırmacılar çalışmalarında Guguk Kuşu Algoritmasını kullanarak bir çok problem çözmüşlerdir. Bu çalışmalardan bazıları; Demirtaş ve Zengin (2016); Karagül (2014); Tuna (2014); Berrazouane ve Mohammedi (2014); Chandrasekaran ve Simon (2012); Basu ve Chowdhury (2013); Boz ve Çimen (2017) ve Erdoğmuş (2016) tarafından gerçekleştirilmiştir.

Guguk Kuşu Algoritmasının sözde kodu, Sözde Kod 2'de gösterilmektedir.

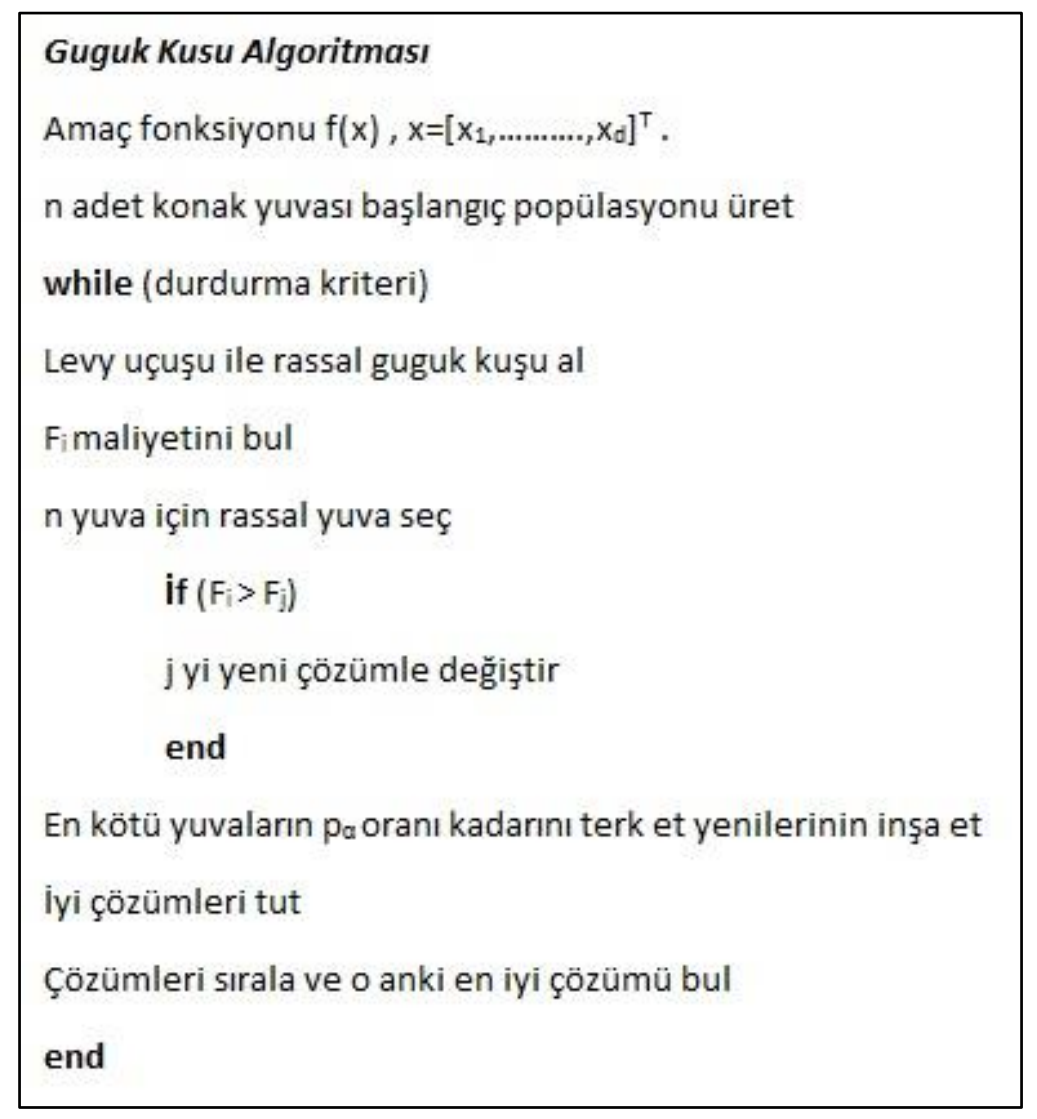

Sözde Kod 2. Guguk Kuşu Algoritması

\section{Uygulama}

A ̆g ve dal sistem olarak tasarlanabilen su dağıtım şebekeleri; hesaplama aşamasında şebekede kullanılan borulara ait çap, uzunluk ve pürüzlülük değerleri belirlidir. Su talebine ve borulara ait 
bilgiler 1şığında şebeke çözülürken Süreklilik ve Enerjinin Korunumu prensipleri göz önüne alınır. (Güney ve Koç, 2001).

- Süreklilik Şartı: Şebekedeki dügüum noktalarına giren debilerle çıkan debilerin toplam eşittir. $(\Sigma \mathrm{Q}=0)$

- Enerjinin Korunumu Şartı: Şebekeye ait her gözde saat yönü artı (+) alınarak hesaplanan enerji kayıplarının toplamı sıfıra eşittir. $\left(\Sigma h_{k}=\Sigma K^{n}=0\right)$

İkinci prensipte yer alan enerji kaybı ifadesi doğrusal olmayan bir denklemdir ve kullanılan enerji kaybı denklemlerine göre belirlenen $\mathrm{K}$ ve $\mathrm{n}$ değişkenlerinden oluşur. Borularda oluşan enerji kayıplarının hesabında, Darcy-Weisbach denklemi kullanılıyorsa Denklem 8 ile ifade edilen K parametresi ve $n=2$ alınır.

$$
K=\frac{16 f L}{2 g \Pi^{2} D^{5}}
$$

Williams-Hazen denklemi için ise Denklem 9' da belirtilen K parametresi ve $n=1.85$ alınır.

$$
K=\frac{L}{0.094 C^{1.85} D^{4.87}}
$$

Sunulan bu çalışmada literatürde yaygın şekilde çözülen, düğüm noktalarının yönler Şekil 1'de verilen iki gözlü ve 5 borudan oluşan örnek şebeke çözülmüştür. Şebekeye 1 numaralı düğümden gelen su, 2, 3 ve 4 numaralı düğümlerden çekilmektedir. Şebekenin düğüm noktalarına ait debiler Tablo 1'de bulunmaktadır.

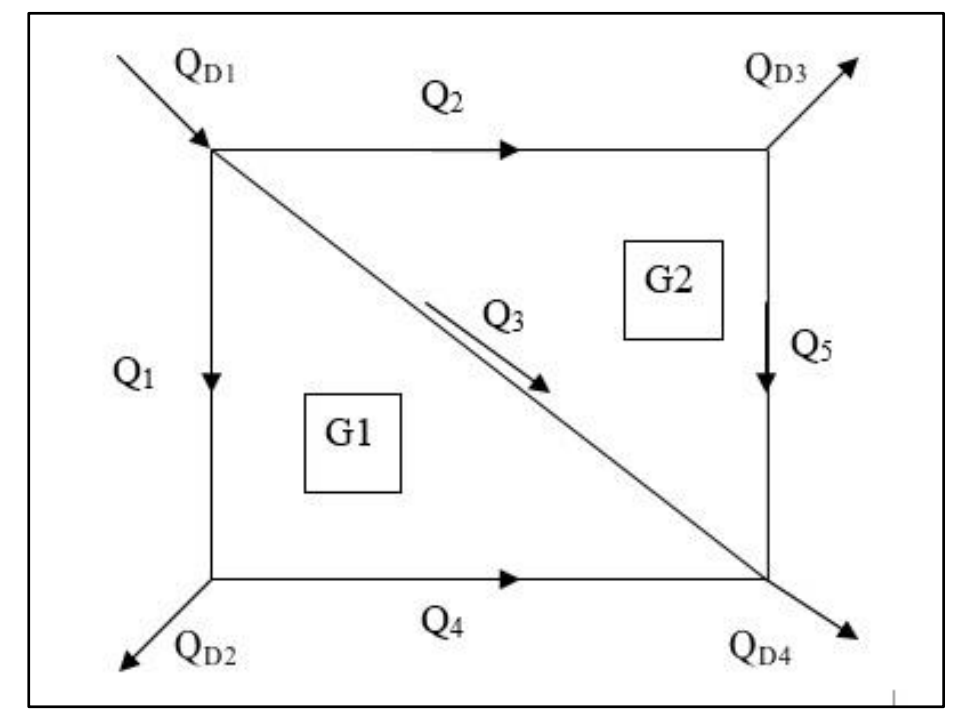

Şekil 1. Örnek Şebeke 
Tablo 1. Düğüm noktaları debileri

\begin{tabular}{rcccc}
\hline Nokta & $\mathbf{Q}_{\mathbf{d} 1}$ & $\mathbf{Q}_{\mathbf{d} 2}$ & $\mathbf{Q}_{\mathbf{d} 3}$ & $\mathbf{Q}_{\mathbf{d} 4}$ \\
\hline Debi & $1001 / \mathrm{s}$ & $301 / \mathrm{s}$ & $301 / \mathrm{s}$ & $401 / \mathrm{s}$ \\
\hline
\end{tabular}

Şebekede bulunan boruların özelikleri Tablo 3`de verilmiştir.

Tablo 2. Şebeke boru özellikleri

\begin{tabular}{rccccc}
\hline Boru No & $\mathbf{1}$ & $\mathbf{2}$ & $\mathbf{3}$ & $\mathbf{4}$ & $\mathbf{5}$ \\
\hline $\mathbf{D}(\mathbf{m m})$ & 300 & 300 & 200 & 100 & 100 \\
$\mathbf{L}(\mathbf{m})$ & 125 & 200 & 175 & 150 & 270 \\
$\mathbf{f}$ & 0.02 & 0.02 & 0.02 & 0.02 & 0.02 \\
\hline
\end{tabular}

Çalışma kapsamında çözülen su dağıtım şebekesine ait amaç fonksiyonu Denklem 10'da verilmiştir.

$$
f=K(2) * Q(2)^{2}+k(5) * q(5)^{2}-K(1) * Q(1)^{2}-K(4) * Q(4)^{2}
$$

Verilen şebeke Koç ve ark.(2003) tarafından Hardy Cross, Newton ve Genetik Algoritma yöntemleriyle çözülmüş olup; bu çalışmadan da Darcy Weisbach denklemi kullanılarak Ateşböceği ve Guguk Kuşu algoritmaları ile çözülmüştür. Algoritmalardaki parametrelere ait bilgiler Tablo 3 'te detaylı olarak yer almaktadır.

Tablo 3. Algoritma Parametreleri

\begin{tabular}{lc|lc}
\hline \multicolumn{2}{c}{ Ateş Böceği Algoritması } & \multicolumn{2}{c}{ Guguk Kuşu Algoritması } \\
\hline Populasyon Boyutu & 50 & Populasyon Boyutu & 50 \\
İterasyon Sayısı & 400 & İterasyon Sayıs1 & 200 \\
Toplam Çözüm Sayısı & 20000 & Toplam Çözüm Sayısı & 20000 \\
$\beta_{0}$ & 0.2 & $p_{a}$ & 0.25 \\
$\gamma$ & 1 & & \\
\hline
\end{tabular}

\section{Tartışma ve Sonuçlar}

Sunulan bu çalışmada örnek basit bir su dağıtım şebekesi iki sezgisel optimizasyon algoritması kullanılarak çözülmüştür. Algoritmaların sonuçları ve bilgi işlem süreleri kendi aralarında karşılaştırılırken; algoritmaların kullanılması sonucu bulunan boru debileri, literatürdeki Koç ve ark. (2003) tarafından Genetik Algoritma, Newton yöntemi sonuçları ile karşılaştırılmıştır.

Çalışmada kullanılan çözüm algoritmaları maksimum iterasyon sayısınca, toplam çözüm sayısı olan 20000 çözüme ulaşılıncaya kadar 100’er kez çalıştırılmıştır. Kullanılan algoritmalara ait 
ortalama, en iyi ve en kötü fonksiyon değerlerinin yakınsama grafikleri Şekil 2'de verilmiştir. Şekil 2'deki ortalama değerler incelendiği zaman Guguk kuşu algoritması ortalama 9. İterasyonda yakınsarken ateş böceği algoritması ortalama 103. İterasyonda yakınsamaktadır.

Çalışmada kullanılan Ateş Böceği ve Guguk Kuşu Algoritmalarına ait optimal sonuçlar Tablo 4'te verilmiştir. Kullanılan algoritmalar karşılaştırıldığı zaman guguk kuşu algoritmasının bilgi işlem süresinin daha kısa ve gerçek çözüme daha yakın sonuçlar verdiği görülmektedir.

Kullanılan algoritmalarla literatürdeki diğer algoritmalar ile karşılaştırıldığı zaman guguk kuşu algoritması sonuçlarının Hardy-Cross ve Newton yöntemi sonuçları ile örtüştüğü belirlenmiştir.

Tablo 4. Ateş Böceği ve Guguk Kuşu Algoritmalarının Sonuçları ve Literatürdeki Diğer Sonuçlar

\begin{tabular}{lccccc}
\hline & ABA & GKA & HC & GA & N \\
\hline $\mathbf{Q}_{\mathbf{1}}$ & 35.39 & 35.46 & 35.46 & 35.56 & 35,46 \\
$\mathbf{Q}_{\mathbf{2}}$ & 33.91 & 33.93 & 33.93 & 34.00 & 33.93 \\
$\mathbf{Q}_{\mathbf{3}}$ & 30.70 & 30.61 & 30.61 & 30.44 & 30.61 \\
$\mathbf{Q}_{\mathbf{4}}$ & 5.39 & 5.46 & 5.46 & 5.56 & 5.46 \\
$\mathbf{Q}_{\mathbf{5}}$ & 3.91 & 3.93 & 3.93 & 4.00 & 3.93 \\
\hline Bilgi İşlem (sn) & $2.6099^{\prime}$ & $0.3535{ }^{\prime}$ & - & - & - \\
\hline
\end{tabular}

ABA: Ateş Böceği Algoritması, GKA: Guguk Kuşu Algoritması, HC: Hardy-Cross Yöntemi, GA: Genetik Algortima, N: Newton Yöntemi

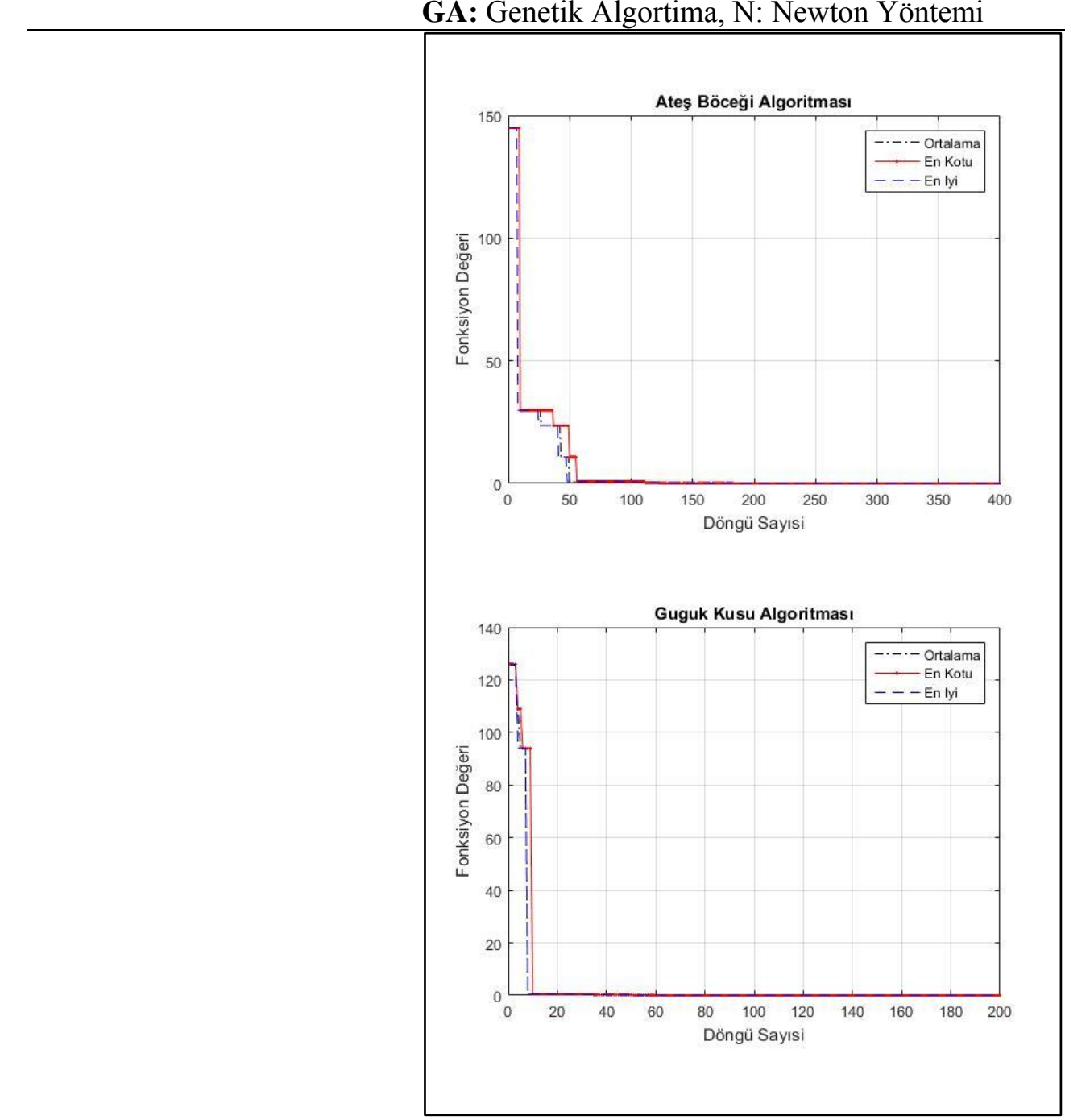

Şekil 2. Algoritmaların İtrerasyon-Yakınsama Grafiği 
Seçilen şebekede kullanılan algoritmalardan Guguk Kuşu algoritmasını kullanılması önerilmektedir. Daha karmaşık şebekelerin, bu çalışmada kullanılan sezgisel optimizasyon algoritmaları ile çözülmesi, bu algoritmaların etkinliği hakkında daha sağlıklı sonuçların elde edilmesine olanak sağlayacağı düşünülmektedir.

\section{Kaynaklar}

Afshar, M.H. and Marino, M.A., (2005). A Convergent Genetic Algorithm for Pipe Network Optimization, Scientia Iranica, 12 (4), 392-401.

Ayvaz, M.T., Karahan, H., Gürarslan, G., (2007). Su dağıtım şebekelerinin armoni araştırması optimizasyon tekniği ile optimum tasarımı, 5. Kentsel Altyapı Ulusal Sempozyumu, Hatay.

Baek, C.W., Jun, H.D. and Kim, J.H., (2010). Development of a PDA Model for Water Distribution Systems Using Harmony Search Algorithm, KSCE Journal of Civil Engineering, 14 (4), 613-625.

Belen, M.A., Alıcı, M., Cor, A., Güneş, F., (2014), Ateşböceği Algoritması ile Mikrodalga Transistör Performans Karakterizasyonu, Eleco 2014 Elektrik - Elektronik - Bilgisayar ve Biyomedikal Mühendisliği Sempozyumu, 27 - 29 Kasım 2014, Bursa

Basu M, Chowdhury A., (2013). "Cuckoo search algorithm for economic dispatch", Elsevier, (60):99-108, 2013.

Berrazouane, S.; Mohammedi, K., (2014). Parameter optimization via cuckoo optimization algorithm of fuzzy controller for energy management of a hybrid power system. Energy Convers. Manag. 2014, 78, 652660.

Boz, A., F., Çimen, M., E., (2017). PSO, CS ve FA Algoritmalartyla Ortak Emiterli BJT'li Yükselteç Tasarımı, Cumhuriyet Üniversitesi Fen Fakültesi Fen Bilimleri Dergisi (CFD), Cilt 38, No. 1 (2017) ISSN: 13001949

Chandrasekaran K., Simon P., (2012). "Multi-objective scheduling problem: Hybrid approach using fuzzy assisted cuckoo search algorithm", Swarm and Evolutionary Computation, 1-16(2012).

Çiftçioğlu, A.Ö., Doğan, E., (2014). Güncel Optimizasyon Tekniklerinin Matematiksel Problemlerin Çözümündeki Performanslarının Klyaslanması, CBÜ Fen Bil. Dergi., Cilt 13, Sayı 2, s 579-591

Demirtaş F., Zengin, K., (2016). Guguk Kuşu Algoritmasının Gezgin Satıcı Problemine Uygulanması ve Simülasyonu, EEB 2016 Elektrik-Elektronik ve Bilgisayar Sempozyumu, 11-13 Mayis 2016, Tokat TÜRKIYE

Değertekini, S.Ö., Lamberti, L., Ülker, M., (2015). Uzay Kafes Yapıların Ateşböceği Algoritması Yöntemiyle Optimizasyonu, XIX. Ulusal Mekanik Kongresi 24-28 Ağustos 2015, Karadeniz Teknik Üniversitesi, Trabzon

Erdin, H.E., (2001). Şehir Planlamada Su ve Kanalizasyon Sistemleri Proje Eşiklerinin Değerlendirilmesi, Yüksek Lisans Tezi, Dokuz Eylül Üniversitesi Fen Bilimleri Enstitüsü, İzmir, 2001.

Erdoğmuş, p., (2016). Doğadan Esinlenen Optimizasyon Algoritmaları ve Optimizasyon Algoritmalarının Optimizasyonu, Düzce Üniversitesi Bilim ve Teknoloji Dergisi, 4 (2016) 293-304

Ezzeldin, R., Djebedjian, B. and Saafan, T., (2013). Integer Discrete Particle Swarm Optimization of Water Distribution Networks, J. Pipeline Syst. Eng. Pract., 04013013, 1-11.

Farahani, S.M., Nasiri, B., Abshouri, A.A., and Meybodi, M.R., (2011). An improved firefly algorithm with directed movement, IEEE, 978-1-61284-836-5/11, 2011.

Geem, Z.W., (2009). Particle -swarm harmony search for water network design, Engineering Optimization, No.4, April 2009, 297-311.

Gandomi, A.H., Yang, X.S., and Alavi, A.H., (2011). Mixed variable structural optimization using firefly algorithm, Computers and Structures, Vol. 89, Issues 23-24, 2325-2336, 2011.

Gandomi, A.H., Yang, X.S. and Alavi, A.H., (2013)."Cuckoo Search algorithm: a metaheusristic approch to solve structural optimization problems," Springer-Verlag, vol. 29, p. 18, 2013-01.

Güney, M.Ş. ve Koç, A.C., (2001), "Pompa ve Basınç Düşürücü Vana İçeren Su Dağıtım Şebekelerinin Farklı Yaklaşımlarla Hesaplanması", Türkiye İnşaat Mühendisliği XVI. Teknik Kongresi, ODTÜ, Ankara. 
Kahraman, A.M. ve Özdağlar, D., (2004). Su Dağıtım Sistemlerinin Genetik Algoritma ile Optimizasyonu, DEÜ Mühendislik Fakültesi Fen ve Mühendislik Dergisi, 6 (3), 1-18.

Karahan, H. Ayvaz, M.T. ve Ceylan, H. (2005), "Su Dağıtım Şebekelerinin Genetik Algoritma ile Optimum Tasarımı", II. Ulusal Su Mühendisliği Sempozyumu, Gümüldür/ İzmir, ss. 577-587.

Karagül, K., (2014). "Guguk Kuşu Algoritması: Bir Plastik Atık Toplama Uygulamas1," 15th International Symposium on Econometrics, Operations Research and Statistic, Isparta, Turkey, vol. 15, pp. 775-784, 22-25 May 2014.

Karaaslan E., Zengin, K., (2016). Ateş Böceği Algoritması ile Haftalık Ders Programı Hazırlama, EEB 2016 Elektrik-Elektronik ve Bilgisayar Sempozyumu, 11-13 Mayıs 2016, Tokat TÜRKIYE

Khadwilard, A., Chansombat, S., Thepphakorn, T., Chainate, W., Pongcharoen, P. (2012). Application of Firefly Algorithm and itsparameter setting for job shop scheduling. 49-58.

Koç, A.C., Karahan, H., Ceylan, H., (2003). Su Dağıtım Şebekelerinin Genetik Algoritma İle Tasarımı, I. Ulusal Su Mühendisliği Sempozyumu, 22-26 Eylül 2003 Gümüldür / İZMİR.

Lukasik, S. and Zak, S., (2009). Firefly algorithm for continuous constrained optimization tasks , In Proceeding of Springer, 169-178, 2009.

Tuna, P., Ö., (2014). Guguk Kuşu (Cuckoo) Algoritması İle Bulanık Sistem Optimizasyonu, Bilecik Şeyh Edebali Üniversitesi Fen Bilimleri Enstitüsü, Yüksek Lisans Tezi, Bilecik, 2014.

Özdağlar, D., Benzeden, E., Kahraman A.M., (2006). Kompleks Su Dağıtım şebekelerinin Genetik Algoritma ile Optimizasyonu, IMO Teknik Dergi, 3851-3867, Yaz1 253.

Sevük, S. ve Altınbilek, D., (1977). Su Dağıtım şebekeleri Projelendirme ve Bilgisayarla Çözüm Esasları, Orta Doğu Teknik Üniversitesi Mühendislik Fakültesi Yayınları, No: 56.

Simpson, A.R., Dandy, G.C., and Murphy, L.J., (1994). Genetic algorithms compared to other techniques for pipe optimization, J. Water Resour. Plann. Manage., 120(4), 423-443.

Suribabu, C.R., (2010). Differential evolution algorithm for optimal design of water distribution networks, Journal of Hydroinformatics, 12 (1), 66-82.

Suribabu, C.R., (2012). Heuristic-Based Pipe Dimensioning Model for Water Distribution Networks, Journal of Pipeline System Engineering and Practise, 3(4), 115-124.

Uz, F.E., (2014). Izgara Sistemlerin Ateş Böceği Algoritması Optimizasyon Yöntemi ile Optimum Boyutlandırılması, Yüksek Lisans Tezi, Celal Bayar Üniversitesi fen Bilimleri Enstitüsü, Manisa, 2014.

Vasan, A. and Simonovic, S.P., (2010). Optimization of Water Distribution Network Design Using Differential Evolution, Journal of Water Resources Planning and Management, 279-287.

Xin-She, Y., Xingshi, H. (2013). Firefly Algorithm: Recent Advances and Applications, Int. J. Swarm Intelligence, Vol. 1, No. 1, 36-50.

Yang, X. S., (2008). Nature-Inspired Metaheuristic Algorithms, Luniver Press, UK.

Yang,X.S. and Deb, S., (2009). "Cuckoo Search via L'evy Flights," Nature \& Biologically Inspired Computing, pp. 210 - 214, 9-11 Dec. 2009.

Yang,X.S., (2009). "Harmony Search as a metaheusristic algortihm Music-inspried harmony search: theory and application," 2009.

Yang, X.S., (2009). Firefly Algorithms for Multimodal Optimization, Proc. 5th Symposium on Stochastic Algorithms, Foundations and Applications, (Eds. O. Watanabe and T.Zeugmann), Lecture Notes in Computer Science, 5792: 169-178.

Yang, X.S., (2010). Engineering Optimisation: An Introduction with Metaheuristic Applications, John Wiley and Sons, USA.

Yang, X.S., and He, X., (2013). Firefly algorithm: Recent advances and applications, International Journal of Swarm Intelligence, Inderscience Publishers, Artificial Intelligence and Intelligent Systems, Vol. 1, 3650, Science, Engineering and Technology, 2013.

Yang, X.S., (2014). Nature-Inspried Optimization Algorithms, 1st Edition," Elsevier, 20 Feb 2014.

Yılmaz, V., (2015). Su dağıtım Şebekelerinin Metasezgisel Yöntemlerle Optimizasyonu, Doktora Tezi, Selçuk Üniversitesi, Fen Bilimleri Enstitüsü, Konya.

Zheng, F., Simpson, A.R. and Zecchin, A., (2011). Performance Study of Differential Evolution with Various Mutation Strategies Applied to Water Distribution System Optimization, World Environmental and Water Resources Congress 2011, California-ABD, 166-176.

Zheng, F., Simpson, A.R. and Zecchin, A., (2012). A performance comparison of differential evolution and genetic algorithm variants applied to water distribution system optimization, World Environmental and Water Resources Congress 2012, New Mexico, 2954-2963.

Zheng, F., Zecchin A.C. and Simpson, A.R., (2013). Self-Adaptive Differential Evolution Algorithm Applied to Water Distribution System Optimization, Journal of Computing in Civil Engineering, 148-158. 